\title{
How do you say in english? Uma experiência educomunicacional em Língua Inglesa no IFRS - Campus Sertão
}

\author{
Maísa Helena Brum ${ }^{1}$ \\ Felipe Batistella Alvares ${ }^{2}$
}

\section{Resumo}

Este relato apresenta uma experiência educomunicacional realizada na disciplina de Língua Inglesa I em conjunto com a disciplina de Áudio, Fotografia e Audiovisual, com duas turmas de primeiro ano do Curso Técnico em Manutenção e Suporte em Informática - integrado ao Ensino Médio, do Instituto Federal do Rio Grande do Sul (IFRS) - Campus Sertão. A experiência educomunicacional tem como aporte teórico a perspectiva dos Multiletramentos (COPE; KALANTZIS, 2009) e a aprendizagem criativa (RESNICK, 2017). A fim de produzir um programete bilíngue para a rádio da escola, os alunos elencaram expressões coloquiais e provérbios da língua inglesa como as temáticas escolhidas para o programa a ser criado. A experiência educomunicativa realizou-se em cinco momentos: 1) pesquisa de expressões coloquiais e provérbios da língua inglesa no laboratório de informática da instituição; 2) seleção das expressões por cada aluno e escrita do roteiro do programa; 3) prática oral das expressões (entonação e ritmo); 4) gravação em estúdio; e 5) edição dos áudios em laboratório de informática. Essa produção educomunicativa fomentou a autonomia dos alunos como produtores de seu próprio programa de rádio, promovendo o desenvolvimento e a prática da oralidade na língua inglesa, bem como 0 engajamento dos alunos no uso apropriado de ferramentas tecnológicas, como softwares de edição de áudio.

Palavras-chave: Língua Inglesa. Educomunicação. Multiletramentos.

\section{Abstract}

This experience report presents a radio educational program experience developed within two disciplines (English Language and Audio Edition and Manipulation, Video and Image) in the Technical High School Course of Information Systems Operation, Maintenance and Support of the Federal Institute of Rio Grande do Sul Sertão Campus. This work follows a theoretical approach based on Multiliteracies (COPE; KALANTZIS, 2009) and Creative Learning perspectives (RESNICK, 2017). With the aim of producing a bilingual radio program for the Campus radio, the students chose colloquial expressions and proverbs in English as the thematic of the program. The radio educational program experience was developed based on five moments: 1) research of the colloquial expressions and proverbs at the school's computer laboratory; 2) selection of the expressions by each student and the program's written script; 3) oral practice (intonation and rhythm); 4) recording at the radio's studio; and 5) audio editing at the school's computer laboratory. This production resulted in students' autonomy as producers of their own radio program, promoting their oral practice and development of English language, as well as their engagement and growth towards the proper use of technology tools.

Key-words: English Language. Radio education. Multiliteracy.

\footnotetext{
1 Doutora em Letras. Instituto Federal do Rio Grande do Sul - Campus Sertão. E-mail: maisa.brum@sertao.ifrs.edu.br.

2 Doutor em Educação. Instituto Federal do Rio Grande do Sul - Campus Sertão. E-mail: felipe.alvares@sertao.ifrs.edu.br.
} 


\section{॥ LÍNGUATEC}

1 Contextualização

Considerando o entendimento de educomunicação como "um campo de reflexão e intervenção social decorrente de novos modos de organizar, distribuir e receber 0 conhecimento e a informação" (CITELLI, 2014, p. 70), este relato tem como objetivo apresentar uma experiência educomunicacional realizada nas disciplinas de Língua Inglesa I e Áudio, Fotografia e Audiovisual, com duas turmas de primeiro ano do Curso Técnico em Manutenção e Suporte em Informática (TMSI) - Integrado ao Ensino Médio, do Instituto Federal de Educação, Ciência e Tecnologia do Rio Grande do Sul (IFRS) - Campus Sertão. 0 Campus Sertão está situado no Distrito de Engenheiro Luiz Englert, município de Sertão, a 25 quilômetros de Passo Fundo, região Norte do Estado do Rio Grande do Sul e integra a Rede Federal de Educação Profissional, Científica e Tecnológica.

Essa experiência educomunicacional está conectada ao projeto de ensino Rádio Conexão que consiste em promover atividades de produção radiofônica (rádio escolar) a fim de ampliar as possibilidades pedagógicas realizadas no Campus-Sertão. Dessa forma, o projeto constitui-se como uma plataforma de apoio às ações de educomunicação e tecnologia, com foco em práticas de sala de aula.

A atividade relatada foi realizada de maneira interdisciplinar, contando com a colaboração dos professores da disciplina de Língua Inglesa I e de Áudio, Fotografia e Audiovisual. Essas disciplinas mostram-se essenciais para a construção do perfil profissional do discente do curso de TMSI, visto que o inglês é amplamente utilizado em linguagens de programação e na área da informática como um todo. Já a prática de manipulação e edição de sistemas multimídias também é uma habilidade necessária para o profissional técnico da área, segundo uma das competências do perfil do egresso que compõem a proposta político pedagógica (PPC) do curso de TMSI, “Ser capaz de utilizar recursos multimídia nas suas atividades profissionais"3.

A seguir, apresentamos as abordagens teóricas que serviram de alicerce para o desenvolvimento da atividade.

\footnotetext{
3 PPC do curso de TMSI do Campus-Sertão, https:/lifrs.edu.br/sertao/wpcontent/uploads/sites/7/2020/03/TMSI-ano-2018.pdf.
} 
2 Aporte teórico

Compreendemos as duas abordagens discutidas nesta seção como teorias que fundamentam a atividade desenvolvida, as quais também foram, metodologicamente, nos auxiliando na condução no trabalho de sala de aula. Cope e Kalantzis (2009) afirmam que, com o passar dos anos, novas tecnologias têm surgido, e, consequentemente, novas práticas comunicativas começaram a ser desempenhadas na sociedade. Com essas novas práticas, diferentes tipos de letramentos emergiram, os quais foram incorporados em novas práticas sociais - maneiras de trabalhar em novas e transformadas formas de uso da linguagem, novas maneiras de participar como cidadão em espaços públicos, e também, talvez, em novas formas de identidade e personalidade 4 (COPE; KALANTZIS, 2009, p. 167). Nesse sentido, promover práticas multiletradas no contexto escolar é essencial, dada a diversidade linguística e cultural dos discentes, bem como a influência de novas tecnologias comunicativas no âmbito da educação.

Segundo Monte Mor (2010, p. 28), a

necessidade de acesso às novas tecnologias, às novas formas de comunicação, ao conhecimento por elas gerado alia-se ao estímulo por saber a língua inglesa, reconhecido como um idioma de amplo trânsito na comunicação e linguagem tecnológica.

Nesse entendimento, os multiletramentos, além de promover uma aprendizagem situada, crítica e conectada às tecnologias, também pode propiciar um ambiente escolar de maior inclusão, estímulo e engajamento social. Vale ressaltar que vivemos em um contexto social que, apesar de não atingir a população de forma plena, é permeado por artefatos tecnológicos como smartphones, notebooks e outros equipamentos digitais (conectados à internet), os quais têm provocado a emergência de novas formas de comunicação, seja por mensagem de texto, por mensagem de áudio ou até mesmo por vídeo, sendo esta, uma condição que nos desafia a repensar também as formas de educar.

\footnotetext{
${ }^{4}$ Nossa tradução. No original: "They are embodied in new social practices - ways of working in new or transformed forms of employment, new ways of participating as a citizen in public spaces, and even perhaps new forms of identity and personality".
} 
Deste modo, para pensar um ambiente de aprendizagem que dialogue com este cenário tecnológico, buscamos no conceito de educomunicação a fundamentação para a prática pedagógica aqui discutida. Educomunicação é um conceito que cria um diálogo entre os campos da educação e da comunicação; de acordo com Soares (2002), pode ser compreendido como

[...] o conjunto das ações inerentes ao planejamento e avaliação de processos, programas e produtos destinados a criar $e$ a fortalecer ecossistemas comunicativos em espaços educativos presenciais ou virtuais, assim como a melhorar o coeficiente comunicativo das ações educativas, incluindo as relacionadas ao uso dos recursos da informação no processo de aprendizagem (p. 43).

Este campo teórico auxilia a pensar e aplicar a linguagem da comunicação em processos escolares, proporcionando-nos à apropriação e ao uso de ferramentas e estratégias - tradicionalmente realizadas pelos campos do jornalismo, da televisão, da publicidade, do rádio, do cinema, etc. - para promover situações de aprendizagem. Vale frisar, não é apenas usar a tecnologia. Evidentemente, a tecnologia nos ajuda em vários sentidos, no entanto, a ideia de apropriar-se da educomunicação tem como objetivo apresentar alternativas educacionais aos métodos tradicionais de ensino que priorizam a transmissão de informações e, assim, estimular o corpo discente a utilizar as informações para ler o mundo, para resolver problemas, para produzir conhecimentos.

Entenda-se por Educomunicação um conceito mais abrangente para pensar os fenômenos de ensino-aprendizagem sob as circunstâncias que matizam a vida contemporânea em sua pluralidade de dispositivos técnicos, estímulos à visualidade, desafios suscitados pelos circuitos digitais, instigações provocadas pelas estratégias de produção, circulação e distribuição da informação e do conhecimento (CITELLI, 2014b, p. 9)

No contexto de uma aprendizagem conectada às tecnologias, a aprendizagem criativa combina “uma exploração curiosa com uma experiementação lúdica e uma investigação sistemática" (RESNICK, 2017) e busca perceber as possibilidades do uso das tecnologias como formas de expansão do pensamento e da expressão criativa dos estudantes. Para Resnick (2017), o foco não deveria recair sobre quais tecnologias as crianças estão usando, mas sim na maneira como essas crianças utilizam as ferramentas tecnológicas para construir 
conhecimento. Com base nesta perspectiva, a experiência educomunicacional desenvolvida em nosso contexto de ensino buscou relacionar o uso da tecnologia de edição de áudios e a prática situada da língua inglesa a fim de construir um programete bilíngue para a rádio escolar do Projeto Rádio Conexão.

3 Metodologia e Desenvolvimento das atividades

A atividade foi desenvolvida com duas turmas de primeiro ano do Curso Técnico em Manutenção e Suporte em Informática - integrado ao Ensino Médio, do IFRS - Campus Sertão, nos anos de 2018 e 2019. As turmas, em média, possuíam 25 alunos cada, com idades variando entre 14 a 16 anos. Em relação ao nível de proficiência em língua inglesa, os alunos, em sua maioria, apresentavam nível intermediário e mostraram-se interessados e engajados na prática oral da língua inglesa, bem como no uso das tecnologias propostas para o projeto.

No que tange às ferramentas tecnológicas disponíveis no Campus - Sertão, os alunos contam com cinco laboratórios de informática disponíveis para uso, além do ambiente da Rádio Conexão, onde o estúdio da rádio escola está localizado. Para esta atividade, utilizamos um dos laboratórios de informática do Campus para os momentos 1, 2 e 5 ; e o estúdio da rádio para o momento 4 da experiência educomunicativa, conforme descrição a seguir.

A experiência educomunicativa realizou-se em cinco momentos: 1) levantamento de expressões coloquiais e provérbios da língua inglesa; 2) escrita do roteiro do programa; 3) prática oral das expressões em língua inglesa; 4) gravações dos áudios em estúdio; e 5) edição dos áudios.

No primeiro momento da atividade, os alunos realizaram, em um dos laboratórios de informática da instituição, um levantamento de algumas expressões coloquiais mais utilizadas em inglês (turma 2018) e provérbios da língua inglesa (turma 2019). 0 levantamento das expressões coloquiais e provérbios surgiram de um trabalho prévio realizado com as turmas na disciplina de língua inglesa, com base no livro "How do you say, in English?: Expressões coloquiais e perguntas inusitadas para quem estuda ou ensina inglês!", de autoria de Jose Roberto A. Igreja.

Na sequência, cada aluno escolheu, individualmente, I (uma) expressão coloquial ou I (um) provérbio e, a partir de sua escolha, escreveu o roteiro para a posterior gravação em 
áudio do programete. 0 roteiro da gravação seguiu o modelo da Tabela 1, desenvolvido pelo professor da disciplina de Áudio, Fotografia e Audiovisual.

\begin{tabular}{|l|l|l|}
\hline TEMPO & \multicolumn{1}{|c|}{ TÉCNICA } & \multicolumn{1}{c|}{ CONTEÚDO } \\
\hline IOS & Vinheta-Abertura & Trilha criada pela equipe Rádio Conexão \\
\hline 405 & $\begin{array}{l}\text { Trilha Musical de } \\
\text { fundo (BG). }\end{array}$ & $\begin{array}{l}\text { Você sabe o que significa “A picture is worth a thousand } \\
\text { words" em inglês? } \\
\text { "A picture is worth a thousand words" significa "Uma } \\
\text { imagem vale mais que mil palavras". }\end{array}$ \\
\hline IOS & $\begin{array}{l}\text { Vinheta- } \\
\text { Fechamento }\end{array}$ & \begin{tabular}{l} 
Trilha criada pela equipe Rádio Conexão \\
\hline
\end{tabular}
\end{tabular}

Tabela 1. Exemplo do modelo de roteiro para o programete. Fonte: Autores.

Em um terceiro momento, em sala de aula, os alunos aprenderam e praticaram a entonação e ritmo na língua inglesa, a fim de perceberem os aspectos fonéticos necessários para narrar e gravar o roteiro de seu programete. Foram trabalhados aspectos como os padrões de entonação (falling/rising intonation) em frases afirmativas e a sílaba tônica (stress) das palavras que seriam mais enfatizadas na gravação. Além disso, foi salientado aos alunos a importância de utilizar a entonação adequada também na língua portuguesa, principalmente na frase interrogativa que inicia cada programete (Você sabe o que significa...em inglês?).

A fim de compreender os aspectos relacionados aos padrões de entonação de frases afirmativas na língua inglesa, a professora da disciplina utilizou quatro horas-aula para explicar o conteúdo e desenvolver atividades de prática oral com os discentes em sala de aula. Para esse momento, a professora explicou o que são content e function words, abordando como elas afetam a oralidade na língua, visto que as content words são as palavras que carregam o sentido principal de uma sentença, já as function words são responsáveis por significar as relações gramaticais entre as palavras (CELCE-MURCIA et al., 1996, p. 153). Nessa perspectiva, os alunos identificaram, no roteiro de seu programete, quais seriam as 
content words e quais seriam as function words e refletiram sobre o porquê de enfatizar algumas palavras em detrimento de outras.

Segundo Roach (2009), a entonação refere-se às variações de tom na voz de um falante para expressar ou alterar significados, além disso, a entonação também demonstra emoções e atitudes desse falante. Assim, na sequência dessa aula de língua inglesa, os alunos foram apresentados à definição de entonação e sua função na fala, bem como aos padrões falling e rising na entonação de uma frase. A partir disto, os discentes puderam perceber, por exemplo, que na sentença "A picture is worth a thousand words", a entonação começa com um padrão rising, enfatizando a content word "picture", para ao final da sentença decrescer em entonação (falling), visto que ela se torna uma declaração enfática no padrão de entonação rise-fall (ROACH, 2009).

O próximo passo para a prática oral dos programetes produzidos foi a prática individual da expressão escolhida, isto é, em duas horas-aula, cada aluno teve um momento particular com a professora a fim de praticar a entonação das frases em seu programete. Neste encontro individual, os alunos esclareceram suas dúvidas e puderem realizar uma gravação "teste" utilizando o gravador de voz do celular da professora. Assim, cada aluno teve a oportunidade de ouvir a sua própria voz e compreender os aspectos fonéticos de sua frase e as possíveis mudanças que deveria fazer para a gravação final, em estúdio. Além disso, a professora encorajou os discentes a enviarem a gravação em áudio do programete para o seu WhatsApp pessoal, quantas vezes eles achassem necessário, para fins de revisão e também para que os alunos pudessem ter mais uma oportunidade de praticar a oralidade na língua inglesa antes da gravação em estúdio.

No quarto momento, os alunos foram para o estúdio da Rádio Conexão, acompanhados do professor de Áudio, Fotografia e Audiovisual e da professora de Língua Inglesa, para que pudessem gravar e regravar, quando necessário, os seus roteiros. Por fim, na aula de Áudio, Fotografia e Audiovisual, em um dos laboratórios de informática do Campus, os alunos realizaram a edição dos áudios previamente gravados a fim de inserir a trilha-sonora criada para o programa e deixar o áudio pronto para ir ao ar na Rádio Conexão, no programete intitulado "How do you say... in English?"5. A edição e criação de vinhetas e do próprio

\footnotetext{
${ }^{5}$ Site do Projeto Rádio Coxexão com as produções radiofônicas dos alunos para o programete “How do you say... in English": http://conexao.sertao.ifrs.edu.br/how-do-you-say/
} 
programete foi realizada pelos estudantes usando a ferramenta de software livre Audacity. A Figura 1 ilustra o quarto momento da experiência educomunicacional.

Após a conclusão das peças radiofônicas, os programetes foram veiculados na rádio que é transmitida exclusivamente pela internet ${ }^{6}$. Foram gravados 44 programetes produzidos pelos alunos, porém, destes 45, 29 programetes estão sendo reproduzidos semanalmente na programação da rádio. Este número se deve ao fato de algumas gravações não apresentarem uma boa qualidade de áudio. Para a hospedagem e reprodução da programação também é utilizado o software livre Libretime, o qual permite organizar os áudios em uma agenda fazendo com que a programação seja executada automaticamente.

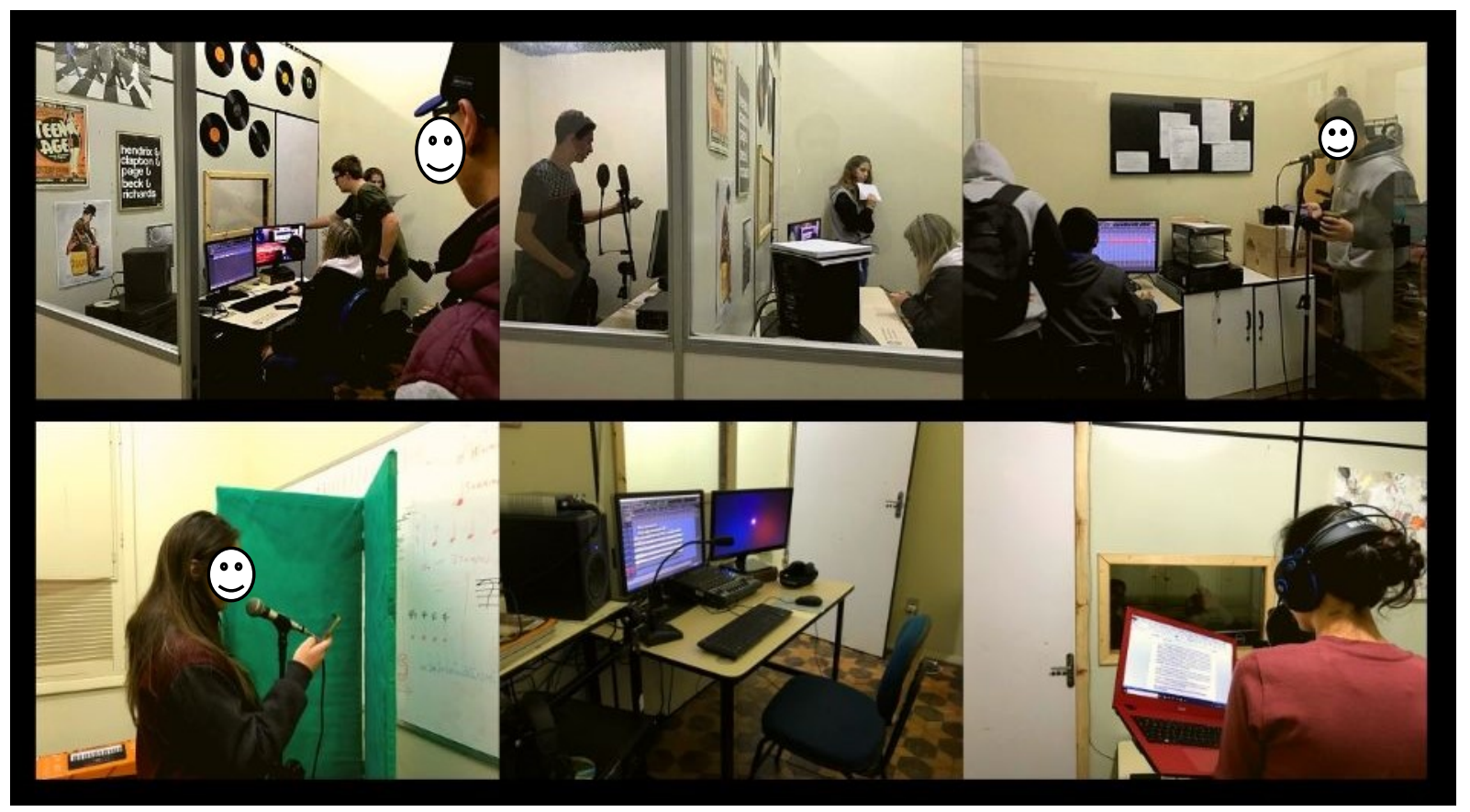

Figura 1. Fotos da gravação dos áudios nas dependências da Rádio Conexão. Fonte: Autores.

\section{Algumas considerações}

A produção educomunicativa resultou na autonomia dos alunos como produtores de seu próprio programete de rádio, promovendo a prática da oralidade na língua-alvo. Em

\footnotetext{
${ }^{6}$ http://conexao.sertao.ifrs.edu.br/player/player.html
} 
relação às habilidades desenvolvidas, a experiência incitou habilidades criativas de trabalho colaborativo e em equipe, que levaram, em última instância a habilidades aprimoradas de oralidade, leitura e escrita em língua inglesa, bem como habilidades tecnológicas, de manipulação de software de edição de áudios.

Outro aspecto positivo da atividade foi o modo como os discentes puderam operacionalizar os estudos de gravação e edição de áudio. Nesta atividade, especificamente, foi possível compreender os conceitos teóricos tratados em aulas expositivas da disciplina de Áudio, Fotografia e Audiovisual a partir da experimentação e da efetiva utilização das informações de modo contextualizado e significativo. Com isso, constatamos que foi possível promover uma situação de aprendizagem criativa, uma vez que os alunos não apenas internalizaram os conteúdos trabalhados, mas também se apropriaram desses conteúdos para resolver o desafio apresentado pelos professores, solucionando-o de modo criativo.

De acordo com Resnick (2017), a criatividade é um processo social, no qual as pessoas colaboram, partilham e constroem o trabalho um do outro. Nessa perspectiva, a atividade desenvolvida também buscou constituir uma ação interdisciplinar ao proporcionar a interação e o trabalho colaborativo entre a disciplina de Língua Inglesa e a disciplina de Áudio, Fotografia e Audiovisual. Por fim, compreende-se que a realização de práticas pedagógicas centradas no aluno, colocando-o em uma postura mais ativa em sala de aula, podem demonstrar maior engajamento e, consequentemente, promover um ambiente propício para o desenvolvimento de processos criativos e reflexivos de aprendizagem.

Referências

CELCE-MURCIA, M., BRINTON, D., GOODWIN, J. Teaching pronunciation: A reference for teachers of English to speakers of other languages. Cambridge, UK: Cambridge University Press, 1996.

CITELLI, A. Educar para a comunicação. Sesc TV, São Paulo, n. 92, v. 10, nov., 2014.

CITELLI, A.; OROFINO, M. I. Uma apresentação entre mediações. In: OROZCO GÓMEZ, G. Educomunicação: recepção midiática, aprendizagens e cidadania. São Paulo: Paulinas, p. 7-12, 2014b. 
COPE, B.; KALANTZIS, M. Multiliteracies: new literacies, new learning. Pedagogies: An International Journal, v. 4, n. 1, p.164-195, 2009.

IGREJA, J. R. A. How do You Say... In English: Expressões coloquiais e perguntas inusitadas para quem estuda ou ensina inglês!. São Paulo: Disal Editora, 2005.

MONTE MÓR, W. Caderno de Orientações Didáticas para EJA Língua Estrangeira - Inglês: etapas complementar e final - São Paulo SME/DOT, 2010.

RESNICK, M. Lifelong Kindergarten: Cultivating Creativity through Projects, Passion, Peers, and Play. The MIT Press: Cambridge, MA, 2017.

ROACH, P. English Phonetics and Phonology. a practical course. Cambridge: C.U.P., 2009.

SOARES, I. O. Gestão Comunicativa e Educação: Caminhos da Educomunicação. Comunicação \& Educação, n. 23, jan.- abr., p. 16-25, 2002.

Data de submissão: 13/04/2020. Data de aprovação: 05/05/2020. 